\title{
An application of unit rate estimation on shareholders' overreaction: Evidence from Tehran Stock Exchange
}

\author{
Mohammad Khodaei Valahzaghard $^{\mathrm{a}^{*}}$ and Amin Shakourloo
}

\begin{abstract}
${ }^{a}$ Assist. Prof. \& Faculty Member, Department of Accounting, School of Management and Human Sciences, Tehran North Branch, Islamic Azad University (IAU), Tehran, Iran

${ }^{b}$ M.Sc. Student, Department of management, School of Management and Human Sciences, Tehran north branch, Islamic Azad University (IAU), Iran CHR ON I C L E A B S T R A C T

Article history:

Received 5 January 2014

Received in revised format 8 March 2014

Accepted 16 March 2014

Available online

20 March 2014

Keywords:

Overreaction

Mean reversion

Industry group

Time series

Unit root

This paper characterizes the stockholders overreaction thorough return and price mean reverting behavior in specified ten major industry groups in Tehran Stock Exchange (TSE). For investigation of mean reversion presence, we use corporate firms from ten specified industry groups traded on the Tehran Stock Exchange and using a random walk with drift model with data over the period 2009-2013 period and recursive estimation in stability diagnostics test. The primary objective of this paper is to investigate mean reversion phenomenon in ten major industries including maximum number of real and nonstrategic investors with two different methods on quarterly return and monthly price time series. The results indicate that mean reversion occurred in the returns of these industry group. In addition, we use two major Unit Root Tests as complementary and final analysis. Out results also indicate that mean reversion takes place, significantly in eight industry groups and price time series in two industry groups follow a random walk process.
\end{abstract}

\section{Introduction}

For years, there have been tremendous efforts to find out about the factors influencing on financial markets and many believe financial information in market is disseminated efficiently and, consequently, it is impossible to predict stock prices. However, this has been under significant criticism under. Some researchers have detected some negative autocorrelation, or "mean reversion," in stock returns over long intervals. The presence of mean reverting process in stock index returns has been under tremendous investigation for many years, which could be either positive or negative. The effects of negative as well as positive autocorrelation of stock returns have been widely documented empirically (Koutmos, 1999). The presence of positive autocorrelation implies partial adjustment of stock prices to their intrinsic values while the negative autocorrelation indicates

*Corresponding author. Tel: +98-912-3443139

E-mail addresses: m khodaei@iau-tnb.ac.ir (M. Khodaei Valahzaghard) 
that stock price changes tend to be followed by predictable volatility in the reverse direction. This is consistent with the view that market agents overreact to price shocks or deviations of stock returns from their long run values, irrationally (De Bondt \& Thaler, 1985, 1987). Recognizing the presence of stock return positive/negative autocorrelation is important to investors for utilizing suitable trading strategies. As an instance, empirical evidence for significant autocorrelation indicates predictable return behavior and, if it is negative, a contrarian trading strategy could be profitable. The evidence of mean reversion was first introduced for the U.S. market by applying U.S. individual firm-level data. DeBondt and Thaler (1985) investigated that past losing stocks over the previous 3-5 years could outperform past winning stocks over a 3-5 years of holding period. Their results state that stock prices would not follow a random walk, but contain a strong mean reverting component.

Fama and French (1988) reported that $25-45 \%$ of the variation of 3 to 5 -year stock returns was predictable from the previous returns. By regressing monthly stock returns on lagged multi-year returns, Fama and French could not detect seasonal effects associated with December selloff of poorly performing securities for tax purposes and time-variations in the market risk premium. Further, Jegadeesh (1991) and Kim et al. (1991) reported very little evidence of mean reversion in the post-World War II era and the was confirmed by McQueen(1992), which contends that the ordinary least squares estimates in Fama and French(1988) would not account for pre and post-World War II differences in stock price volatility.

Despite its popularity in practice, industry analysis has received limited academic attention in finance research particularly in emerging and developing markets such as Tehran Stock Exchange (TSE). Many industry analysts have stated that a group of firms that produce homogenous products (i.e., industry) could determine the market supply of a product. However, in financial economics, the supply (or demand) of an asset is infinitely elastic, since all assets are perfect substitutes. Popular models, whether rational or behavioral, simply grant no role to industries. Nevertheless, researchers commonly control for the "industry effect" in empirical studies, without any theoretical foundation for doing its (e.g., Kahle \& Walking, 1996) ${ }^{1}$.

Theoretically, an industry refers to a group of firms producing homogenous products or close substitutes; practically, a firm rarely produces just one product. Broad industry classifications, such as standard industrial classification (SIC) codes, thus have been used widely to identify homogeneous groups of firms that engage in practice in close businesses. These classification schemes generally reflect broad attributes, such that firms of the same industry may be competitive when they produce close substitutes but cooperative when their products are complements. Whether it is market wide, industry specific, or firm specific in nature, because the product mixes or even the business units of a firm could span a wide range, both vertically and horizontally, it is difficult to foresee how firms might respond to relevant information.

There are tremendous efforts devoted on analyzing mean reversion using size-sorted portfolios (for instance, Fama \& French, 1988; Jegadeesh, 1991; Gangopadhyay, 1996; Gangopadhyay). The amount of research devoted on analyzing mean reversion using industry sorted portfolios has been limited. Only Fama and French (1988) used industry group to investigate for the presence of mean reversion and the difference in methodologies is not inconsequential. As Gropp (2004) illustrates, the implementation of portfolios containing stocks classified by market capitalization and more precisely, the standard methodology applied to rank stocks into their respective deciles, fails to describe for temporary shocks in asset prices implying that subsequent price reversals would be missed, decreasing the likelihood of detecting mean reversion. Much of the controversy on the issue of mean reversion arises because of the speed of reversion, if it exists, may be very slow and many

\footnotetext{
${ }^{1}$ Kahle and Walkling (1996) identify 81 articles published in the five top-tier finance journals during a four-year sample period (1992-1995) that use industry classifications.
} 
econometric approaches may have insufficient power to discriminate a mean reversion process from a random walk process.

In summary, we try to detect various unique industry related patterns in our analysis on TSE, which seem to be new in the literature. The empirical findings indicate that industry returns and prices with various periods in TSE reflect both significant rational and behavioral components differently, but neither rational nor behavioral theories alone can fully explain industry returns and price fluctuation. The results indicate that industries play a dual role in explaining stock returns and prices that deserves further exploration with various methods.

In this paper, we examine for mean reversion in industry stock returns and prices of TSE market for relative short-time based on monthly prices and quarterly return data time series from 2009 to 2013. In addition, we use the TEFIX index in our analysis and our results provide useful information from this independent sample, and they have located in the existing studies on developing markets.

Our search operation for stockholders overreaction thorough mean reversion method takes place in the first ten major industry groups in TSE that have maximum number of stockholders compared with other industries in TSE. These groups include Machinery, Food Products, Chemicals, Construction, Computer, Pharmaceutical Products, Fundamental Metals, Petroleum Products, Banking \& Construction Materials. So we can measure this phenomenon specially and exactly with respect to major number of shareholders in TSE. In particular, we investigate the relationship between the overreaction parameter and market industry group as well as other measures of market frictions. The primarily results for our mean reversion model imply that negative autocorrelation exists in five numbers of ten industries and rest of industry has a positive autocorrelation, but our subsequent analysis estimation results thorough unit root tests implying that mean reversion take place in eight industry group.

\section{Data and methodology}

The contribution of this paper is twofold and our research has two steps. First, we offer a simple approach to estimate an Industry return overreaction correction parameter by proposing stock return dynamic time series model, which incorporates such an effect and performs autocorrelation test on this model. We then conduct a stationary analysis to investigate that whether the industrial stock price time series have a random walk process or not. We document that, at the aggregate level by means of Dickey-Fuller (ADF) \& Phillips-Perron Unit Root Tests on industry stock price time series. We apply the setup to TSE financials stock market data from 2009 to 2013 and first show how the overreaction parameter for each industry can be estimated.

\section{Step 1. Mean reversion econometric model}

In this paper, we provide the empirical framework for the analysis of stockholder overreaction in first research step to motivate our final specification and clarify our model in this method to estimate overreaction. We specify the mean-reverting stock return dynamics that accounts for the overreaction effect:

$R_{t}=\rho\left(R_{t-1}-\mu\right)+\mu+\varepsilon_{t}$

where constant parameter is $\mu, R_{t}$ is stock return computed as the logarithmic difference in the seasonality index for 15 quarters in this study. The focal parameter in our model is $\rho$, which measures the degree of frictions in the market and serial correlation in market returns. If the coefficient is 0 , then the market price completely adjusts to its mean or intrinsic value. The larger value of $\rho$, indicates the larger degree of market frictions and the coefficient is expected to be positive. The negative 
autocorrelation indicates that stock price changes tend to be followed by predictable volatility in the opposite direction. However, the market can exhibit negative serial correlation arising from overreaction of market agents to past information. It is necessary to mention that the market return exhibits a random walk behavior or contains a unit root if is $\rho=1$. Therefore, we form following hypothesis test in this step:

$H_{o}: \rho \geq 0$

$H_{1}: \rho<0$

\section{Step 2. Unit Root Tests}

In the second step, we apply Unit Root Tests in our analysis, specifically Dicky-Fuller and PhilipsPerron unit root test for industry stock price time series. Many economic and financial time series exhibit trending behavior or non-stationary in their mean. Leading examples are asset prices, exchange rates and the levels of macroeconomic aggregates like real GDP. Common trading strategy in finance involves exploiting mean reverting behavior among the prices of pairs of assets, and unit root tests can be used to determine which pairs of assets appear to exhibit mean reverting behavior thorough the following time series model:

$\mathcal{Y}_{t}=C+\delta t+\varphi \mathcal{Y}_{t-1}+\varepsilon_{t}$

which includes a constant and deterministic time trend to capture the deterministic trend under the alternative. The null and alternative hypotheses in second steps and also appropriately to characterize the trend properties of the data at hand is as follows,

$H_{o}: \varphi=1 \Rightarrow y_{t} \sim I(1)$

$H_{1}:|\varphi|<1 \Rightarrow \mathcal{Y}_{t} \sim I(0)$

\section{Augmented Dickey-Fuller (ADF) Unit Root Test}

Following ADF unit root test, the hypothesis of mean reversion in stock prices can be motivated with the following model:

$y_{t}=\beta^{\prime} D_{t}+\rho y_{t-1}+\sum_{j=1}^{p} \psi \Delta y_{t-j}+\varepsilon_{t}$

where $D_{t}$ a vector of is deterministic terms (constant, trend etc.). The $p$ lagged difference terms, $\Delta \mathcal{Y}_{t-j}$ are used to approximate the ARMA structure of the errors, and the value of $p$ is set, so that the error $\varepsilon_{t}$ is serially uncorrelated. This unit root test helps us test for a unit root in the difference of the industrial group price time series. The null hypothesis relating to this test is $p=1$, Acceptance of the null hypothesis implies that the price series in industry groups is non-stationary process and overreaction has no presence. If $p<1$ (alternative hypothesis) then deviations in price series are reversed in the subsequent period and these deviations from their previous values are transitory and will be reversed over time.

\section{Phillips-Perron Unit Root Test:}

Phillips and Perron (1988) developed a number of unit root tests that have become popular in the analysis of financial time series. The Phillips-Perron (PP) unit root tests differ from the ADF tests mainly in how they deal with serial correlation and heteroskedasticity in the errors. In particular, where the ADF tests use a parametric auto-regression to approximate the ARMA structure of the errors in the test regression, the PP tests ignore any serial correlation in the test regression. The test regression for the PP tests is as follows, 
$\Delta \mathcal{Y}_{t}=\beta^{\prime} D_{t}+\rho \mathcal{Y}_{t-1}+u_{t}$

So in this subsection, we examine below hypothesis similarly to ADF Unit Root Test:

$\mathrm{H}_{0}: \rho=1 \quad$ Price series have random walk process

$\mathrm{H}_{1}: \rho<1 \quad$ Mean reversion behavior exist in price series

Before performing two operations, we present descriptive analysis relative to each industry group in time of our research for return and price time series.

\subsection{Descriptive statistics}

We employ TEFIX (Free Float Index) indexes of ten major industry groups in TSE market for our analysis. In free float methodology, market capitalization is calculated by taking the equity's price by the number of shares readily available in the market instead of using all of the shares like the fullmarket capitalization method. The free-float method in this research is seen as a better way of calculating market capitalization because it provides a more accurate reflection of market movements especially for nonstrategic stockholders. When using a free-float methodology, the resulting market capitalization is smaller than what would result from a full-market capitalization method so this approach let us estimate overreaction of ordinary \& nonstrategic stockholder that don't hold their stocks for strategic purpose in long time and more effective in our manner in this field.

In this paper, TEFIX index expressed in local currency and the return data are calculated quarterly from 2009 to 2013. Moreover, the price TEFIX index of TSE is only available from August 2008 onwards. We compute seasonal returns for each industry as the logarithmic difference between start and end season price and these returns series correspond with market index. In addition, these returns presented in Table 1 are averages over all formation periods. We calculate abnormal return via difference between average raw season returns for each industry and TEFIX market index. The average number of firms in an industry (with TEFIX index) varies from 88 to 99 , implying that investing capital in a single industry might not be well diversified. The average monthly returns for industry returns range from $0.182733 \%$ to $2.198172 \%$, with a grand average of 1.065673 for all industries. As a preliminary analysis, we also calculate the abnormal return for each industry based on the difference between average raw return and average market return $\left(R_{A b}=R_{i t}-R_{m t}\right)$. Here fundament metal group have a maximum average abnormal return compared with other industry groups. Last row of Table 1 indicates that the average seasonally abnormal return across all industries is 0.249327 , which rejects the negative and zero average of abnormal return for all industries in TSE in our period.

As reflected by the average number of stockholders, the machinery, construction \& construction materials industry group have the highest number of stockholders while the computer \& pharmaceutical products industry groups records the least number of stockholders. Table 2 provides descriptive statistics of the price monthly time series in each ten industry group. The Jarque-Bera test statistics for normality test indicates deviations from the normal distribution in three industry groups under our study and these groups include Food products, Construction, and Computer. As reflected by the standard deviation, the Petroleum Product, Pharmaceutical \& Computer industry group have the highest volatility while the Banking, Construction \& Construction Materials industry groups records the least volatility. All industry group prices except the Chemicals, Petroleum Products and Banking groups are positively skewed. The kurtosis statistics, which are substantially higher than 3, indicate excess peakness of the industry stock price distribution in Food Products, Construction, Computer \& Construction Materials group. 
Table 1

Industries return time series descriptive statistics

\begin{tabular}{|c|c|c|c|c|}
\hline Industry & Avg. compounded Return & Avg. Ab Return & Std. of compounded Return & Avg. No .of stockholders \\
\hline Machinery & 0.182733018 & -0.63361 & 1.517018198 & 436865 \\
\hline Food Products & 1.307266984 & 0.490922 & 1.799360765 & 175389 \\
\hline Chemicals & 2.011957566 & 1.195612 & 2.701558413 & 154286 \\
\hline Construction & 0.390869343 & -0.42548 & 1.524950733 & 273165 \\
\hline Computer & 0.960787337 & 0.144442 & 2.177496923 & 73273 \\
\hline Pharmaceutical Products & 0.700047519 & -0.1163 & 2.024619272 & 80,482 \\
\hline Fundamental Metals & 2. 198171588 & 1.381826 & 1.674477133 & 148,574 \\
\hline Petroleum Product & 1.808752979 & 0.9924075 & 3.110347189 & 143,658 \\
\hline Banking & 0.808606864 & -0.00774 & 1.556852366 & 742,491 \\
\hline Construction Materials & 0.287536291 & -0.52881 & 1.637907062 & 239,657 \\
\hline$\Sigma$ & 10.65673 & 2.49327 & 19.72459 & 2467840 \\
\hline $\operatorname{Max}$ & 2.198172 & 1.381826 & 3.110347 & 742491 \\
\hline Mean & 0.182733 & -0.63361 & 1.517018 & 73273 \\
\hline$\mu$ & 1.065673 & 0.249327 & 1.972459 & 246784 \\
\hline
\end{tabular}

Table 2

Industry stock price time series descriptive statistics

\begin{tabular}{|c|c|c|c|c|c|c|c|c|}
\hline Industry & Mean & $\operatorname{Max}$ & Min & Std. Div. & Kurtosis & Skewness & J-B Statistic & Prob \\
\hline Machinery & 1584.791 & 2430.500 & 1092.857 & 358.7740 & 2.618102 & 0.798129 & 3.142870 & 0.207747 \\
\hline Food Products & 2355.714 & 3311.714 & 1826.429 & 328.0418 & 4.000462 & 0.934676 & 7.492332 & 0.023608 \\
\hline Chemicals & 4935.932 & 6326.182 & 3317.455 & 949.8026 & 1.810032 & -0.289097 & 2.917219 & 0.232559 \\
\hline Construction & 1792.842 & 2228.375 & 1578.375 & 160.2796 & 4.116158 & 1.249563 & 12.48573 & 0.001944 \\
\hline Computer & 11436.28 & 31500.00 & 7040.000 & $\mathbf{5 5 7 4 . 8 8 8}$ & 6.357150 & 1.945955 & 44.02905 & 0.000000 \\
\hline Pharmaceutical Products & 7636.063 & 10003.40 & 5420.733 & 1262.375 & 2.186853 & 0.018631 & 1.104327 & 0.575703 \\
\hline Fundamental Metals & 3727.507 & 5133.429 & 2365.286 & 737.4794 & 2.273090 & 0.271281 & 1.371284 & 0.503767 \\
\hline Petroleum Products & 9765.625 & 13321.00 & 5358.500 & 2466.024 & 1.898130 & -0.484054 & 3.585588 & 0.166494 \\
\hline Banking & 1314.275 & 1837.333 & 863.0000 & 260.3629 & 2.116457 & -0.097126 & 1.363969 & 0.505613 \\
\hline Construction Materials & 3053.650 & 3804.000 & 2534.375 & 274.3516 & 3.097209 & 0.379198 & 0.974357 & 0.614357 \\
\hline
\end{tabular}

\subsection{Econometric model estimation}

In our study, it is expected that $\rho$ for the return to be positive or to exhibit mean reverting behavior. Therefore, in Table 3 we show the result of estimation of model parameter and statistics for each ten industry group. As see in Table 3, there are five industry groups with negative coefficient: Chemicals, Food Products, Fundament Metals, Constructions \& Computer. It explains that return series in these groups have negative correlation and therefore null hypothesis of no mean reversion $(\rho \geq 0)$ can be rejected for five industries. So we find that mean reversion exist in these groups and exhibit negative correlation. The negative autocorrelation indicates that stock price changes tend to be followed by predictable volatility in the opposite direction. In fact, market agents in each five industries overreact irrationally to price shocks or deviations of stock returns from their long run values. However, these deviations are reverse to fundament value for these five groups after several lags. Therefore, we suggest that a contrarian trading strategy can be profitable in five industries for relatively short time. In addition, we have not found any unity for $\rho$ coefficient, this result shows no random walk process in return series for these industry groups in time of investing.

The Durbin-Watson statistics amounts indicate lack of autocorrelation in disturbance terms in our model estimation for ten-industry group. After estimating that returns possess trend reverting component in separate panels, we use the one-step forecasting method to describe the structural fracture \& coefficient variation values in our model estimation. The results of one-step forecasting are presented in Fig. 1 where in three industrial groups, Medical, Construction and Machinery, the amounts of coefficient were more than critical value in one lag and structural fracture occurred in these industry groups. In addition, structural fracture presence in three industry groups indicates that the standard econometric approaches used to examine presence of mean reversion commonly does not have sufficient power to reject the null hypothesis of a random walk against the alternative of mean reversion. In addition, our estimation results can be changed by employing the various return horizons. Therefore, we correct this gap and possibly providing further support for the presence of mean reversion under the alternative hypothesis by using Dickey-Fuller (ADF) \& Philips-Perron Unit root tests in continuation. By these analyzing from the TSE market, we provide some insight into the behavior of stock prices during our research 3 years horizon. 
Table 3

Panel Test for industrial Mean reversion

\begin{tabular}{cccccccccc}
\hline Industry & $(\rho)$ Estimation & Mean $(\mathrm{e})$ & Variance $(\mathrm{e})$ & $\mathrm{F}$-Stat & Probe & D-W stat & $\mathrm{H}_{0}$ & $\mathrm{H}_{1}$ \\
\hline Construction & 0.044280 & 0.296472 & 0.779893 & 20.46630 & 0.000083 & 1.5637 & Accepted & Rejected \\
Pharmaceutical & 0.006532 & 0.452171 & 1.076933 & 17.60647 & 0.000165 & 2.4497 & Accepted & Rejected \\
Machinery & 0.005573 & 1.064140 & -0.048598 & 828.0777 & 0.000000 & 1.6146 & Accepted & Rejected \\
Chemicals & $\mathbf{- 0 . 0 5 7 0 7 9}$ & $\mathbf{0 . 3 4 7 8 0 8}$ & $\mathbf{0 . 9 6 4 2 6 7}$ & $\mathbf{1 3 . 9 3 6 8 1}$ & $\mathbf{0 . 0 0 0 4 5 8}$ & 1.9597 & Rejected & Accepted \\
Food products & $\mathbf{- 0 . 0 5 6 6 5 2}$ & $\mathbf{0 . 3 2 0 2 9 1}$ & $\mathbf{0 . 8 3 4 6 2 1}$ & $\mathbf{1 0 . 9 4 3 0 4}$ & $\mathbf{0 . 0 0 1 2 4 9}$ & $\mathbf{2 . 3 1 8 1}$ & Rejected & Accepted \\
Banking & 0.790001 & 0.055373 & 0.045049 & 251.1897 & 0.000000 & 2.3725 & Accepted & Rejected \\
Fundamental & $\mathbf{- 0 . 0 8 7 4 0 7}$ & $\mathbf{0 . 3 1 2 7 8 8}$ & $\mathbf{0 . 4 8 2 2 6 8}$ & $\mathbf{6 . 4 2 1 9 0 1}$ & $\mathbf{0 . 0 0 8 9 7 3}$ & $\mathbf{2 . 2 3 7 8}$ & Rejected & Accepted \\
Construction & $\mathbf{- 0 . 0 5 5 1 1 8}$ & $\mathbf{0 . 4 8 2 8 4 5}$ & $\mathbf{0 . 2 6 7 5 6 9}$ & $\mathbf{3 0 . 7 1 3 5 0}$ & $\mathbf{0 . 0 0 0 0 1 2}$ & $\mathbf{2 . 0 5 3 6}$ & Rejected & Accepted \\
Oil & 0.090684 & 0.422393 & 0.183584 & 13.85973 & 0.000469 & 2.3837 & Accepted & Rejected \\
Computer & $\mathbf{- 0 . 0 0 8 2 3 7}$ & $\mathbf{0 . 7 4 9 1 8 4}$ & $\mathbf{0 . 2 4 8 2 2 8}$ & $\mathbf{1 3 3 . 1 0 0 2}$ & $\mathbf{0 . 0 0 0 0 0 0}$ & 1.9467 & Rejected & Accepted \\
\hline
\end{tabular}

Medical

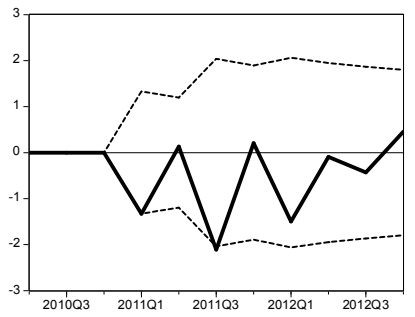

Chemicals

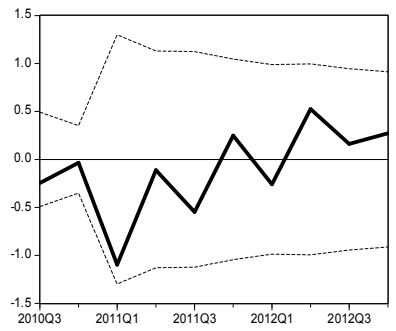

Fundament Metals

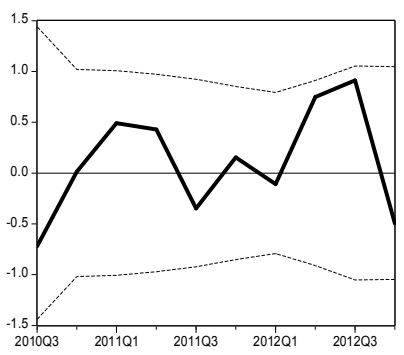

Construction

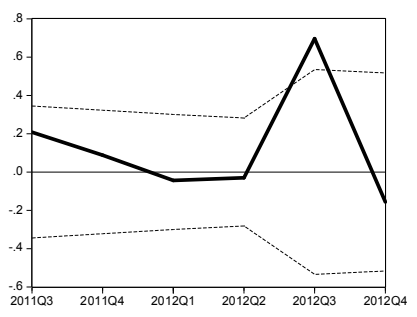

Construction materials

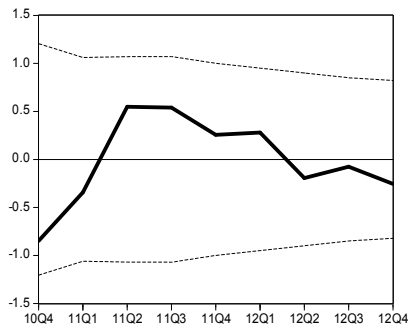

Computer

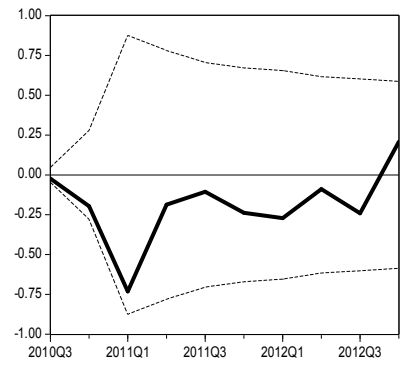

Petroleum Products

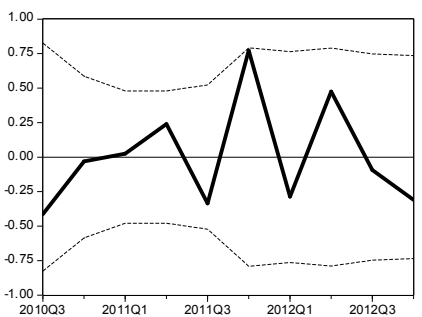

Food

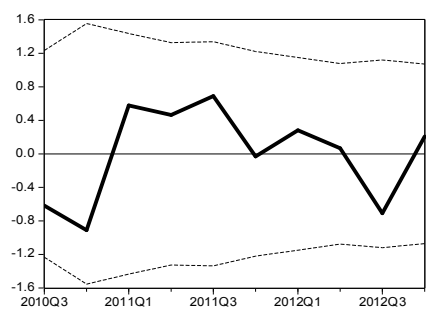

Investments

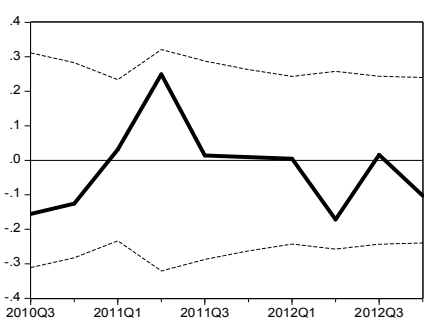

Machinery

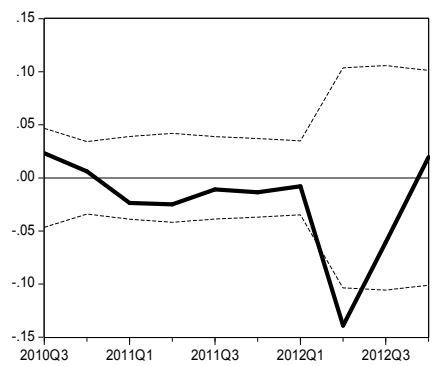

Fig. 1. One step forecasting method estimation results 


\subsection{Dickey-Fuller (ADF) Unit Root Test}

The results for the ADF unit root test are presented in Table 4. According to the results of Table 4, the null hypothesis of no mean reversion can be rejected for 8 groups out of 10 industrial groups. This means that based on ADF unit root test, 8 industrial groups have mean reversion in their price series and deviations in price series in these groups are reversed in subsequent periods. The test statistic both in $5 \& 10$ percent significance level located in critical section only in Construction and Construction Materials groups. In addition, Durbin Watson statistics in Table 4 shows that ADF unit root test estimation for price series in each 10 industrial group was uncorrelated.

Table 4

Dickey-Fuller (ADF) Unit Root Test estimation results

\begin{tabular}{|c|c|c|c|c|c|c|c|}
\hline Industry & $\begin{array}{c}\text { Significance } \\
\text { level } 10 \%\end{array}$ & $\begin{array}{c}\text { Significance } \\
\text { level } 5 \%\end{array}$ & $\begin{array}{c}\text { Dickey \& } \\
\text { Fuller Stat }\end{array}$ & Probe & D-W stat & $\mathrm{H}_{0}$ & $\mathrm{H}_{1}$ \\
\hline Machinery & -2.600658 & -2.925169 & -1.730489 & 0.4086 & 1.824683 & Rejected & Accepted \\
\hline Food Products & -2.600658 & -2.925169 & -2.240409 & 0.1953 & 1.775287 & Rejected & Accepted \\
\hline Chemicals & -2.600658 & -2.925169 & -0.139204 & 0.9388 & 2.042704 & Rejected & Accepted \\
\hline Construction & -2.601424 & -2.926622 & -3.731468 & 0.0068 & 1.988959 & Accepted & Rejected \\
\hline Computer & -2.600658 & -2.925169 & -2.290054 & 0.1793 & 1.944369 & Rejected & Accepted \\
\hline Pharmaceutical Products & -2.603944 & -2.931404 & -1.839360 & 0.3571 & 2.019176 & Rejected & Accepted \\
\hline Fundamental Metals & -2.600658 & -2.925169 & -2.394508 & 0.1487 & 1.770672 & Rejected & Accepted \\
\hline Petroleum Products & -2.600658 & -2.925169 & -1.068825 & 0.7204 & 1.824683 & Rejected & Accepted \\
\hline Banking & -2.600658 & -2.925169 & -1.726879 & 0.4115 & 1.721298 & Rejected & Accepted \\
\hline Construction materials & -2.600658 & -2.925169 & -3.557950 & 0.0105 & 1.5101126 & Accepted & Rejected \\
\hline
\end{tabular}

\subsection{Phillips-Perron Unit Root Test}

The results for the Phillips-Perron Unit Root Test are presented in Table 5. These results are similar to ADF unit root test performed in previous section. According to Table 5, the null hypothesis of no mean reversion can be rejected for 8 groups out of 10 industrial groups. This means that based on Phillips-Perron Unit Root Test, 8 industrial groups have mean reversion in their price series and deviations in price series in these groups are reversed in the subsequent periods. The test statistic both in 5 \& 10 percent significance level located in critical section only in construction and construction materials groups. In addition, Durbin-Watson statistics in Table 5 shows ADF unit root test estimation for price series in each 10 industrial group is uncorrelated.

Table 5

Phillips-Perron Unit Root Test estimation results

\begin{tabular}{|c|c|c|c|c|c|c|c|}
\hline Industry & $\begin{array}{c}\text { Significance level } \\
10 \%\end{array}$ & $\begin{array}{c}\text { Significance level } \\
5 \%\end{array}$ & $\begin{array}{c}\text { Phillips-Perron } \\
\text { Stat } \\
\end{array}$ & Probe & D-W stat & $\mathrm{H}_{0}$ & $\mathrm{H}_{1}$ \\
\hline Machinery & -2.600658 & -2.925169 & -0.913054 & 0.7755 & 1.406967 & Rejected & Accepted \\
\hline Food Products & -2.600658 & -2.925169 & -2.350313 & 0.1612 & 1.775287 & Rejected & Accepted \\
\hline Chemicals & -2.600658 & -2.925169 & -0.139204 & 0.9388 & 2.042704 & Rejected & Accepted \\
\hline Construction & -2.600658 & -2.926622 & -2.943576 & 0.0480 & 1.417893 & Accepte & Rejected \\
\hline Computer & -2.600658 & -2.925169 & -2.290054 & 0.1793 & 1.944369 & Rejected & Accepted \\
\hline Pharmaceutical Products & -2.603544 & -2.931404 & -1.660124 & 0.4445 & 1.664733 & Rejected & Accepted \\
\hline Fundamental Metals & -2.600658 & -2.925169 & -2.441657 & 0.1363 & 1.770672 & Rejected & Accepted \\
\hline Petroleum Products & -2.600658 & -2.925169 & -1.166839 & 0.6810 & 1.824683 & Rejected & Accepted \\
\hline Banking & -2.600658 & -2.925169 & -1.766686 & 0.3921 & 1.721298 & Rejected & Accepted \\
\hline Construction materials & -2.600658 & -2.925169 & -3.77880 & 0.0058 & 1.416126 & Accepted & Rejected \\
\hline
\end{tabular}

\section{Conclusion}

In this paper, we have estimated an overreaction parameter governing the dynamics of stock return time series in ten separate industry groups. In addition, we have examined random walk process in 
this time series and the results have failed to detect a random walk behavior in asset returns. In fact, stock prices did not follow a random walk, but contained a strong mean reverting component. Panel tests for the examination of mean reversion in asset prices have provided definitive evidence for presence of mean reversion and stockholder overreaction in these ten industries for short-term periods in this case. The fact that stock prices experience mean reversion was robust and so we have rejected capital market efficiency for TSE market in our investigation. The primary focus of this paper was on time series analysis, so we hope to provide a measurement of the economic importance of the mean reversion results presented earlier. Such a procedure would confirm the specification of the returns process if the investment strategy increases expected returns.

\section{Acknowledgement}

The authors would like to thank the anonymous referees for constructive comments on earlier version of this paper.

\section{References}

DeBondt, W.F.M., \& Thaler, R. H. (1985). Does the stock market overreact?. Journal of Finance, 40, 793-805.

DeBondt, W.F.M., \& Thaler, R. H. (1987). Further evidence on investor overreaction and stock market seasonality. Journal of Finance, 42, 557-581.

Dickey, D., \& Fuller, W. (1981). Likelihood ratio statistics for autoregressive time series with a unit root. Econometrica, 49, 1057- 1072.

Fama, E., \& French, K. (1988). Permanent and temporary components of stock prices. Journal of Political Economy, 96, 246- 273.

Gangopadhyay, P., \& Reinganum, M. (1996). Interpreting mean reversion in stock returns. Quarterly Review of Economics and Finance, 36, 377- 394.

Gropp, J. (2004). Mean reversion of size-sorted portfolios and parametric contrarian strategies. Managerial Finance, 29, 5 - 21.

Jegadeesh, N. (1991). Seasonality in stock price mean reversion: evidence from the U.S. and the U.K. Journal of Finance, 46, 1427- 1444.

Kim, M., Nelson, C., \& Startz, R. (1991). Mean reversion in stock prices? A reappraisal of the empirical evidence. Review of Economic Studies, 58, 515- 528.

Koutmos, G. (1999). Asymmetric index stock returns: Evidence from the G-7. Applied Economic Letters, 6, 817-820.

Kahle, K.M., \& Walkling, R.A. (1996). The impact of industry classifications on financial research. Journal of Financial and Quantitative Analysis, 31, 309-335.

Kulp-Tag, S. (2007). Short-horizon asymmetric mean reversion and overreactions: Evidence from the Nordic Stock Markets. Meddelanden Working Paper, no. 524.

Liau, Y.-S., \& Yang, J.J.W. (2008). The mean/volatility asymmetry in Asian Stock Markets. Applied Financial Economics, 18, 411-419.

McQueen, G. (1992). Long-horizon mean-reverting stock prices revisited. Journal of Financial and Quantitative Analysis, 27, 1 -18.

Nam, K. (2001). Stock overreaction and contrarian profits: Findings from asymmetric reversal intrinsic in time series. Paper presented at the 2001 FMA Annual Meeting in Toronto, Canada, October.

Nam, K. (2003). The asymmetric reverting property of stock returns. Studies in Nonlinear Dynamics and Econometrics, 6(4), Article 2.

Nam, K., Pyun, C.S., \& Arize, A., (2002). Asymmetric mean-reversion and contrarian profits: ANSTGARCH Approach. Journal of Empirical Finance, 9, 563-588.

Nam, K., Pyun, C. S., \& Avard, S. (2001). Asymmetric reverting behavior of short-horizon stock returns: An evidence of stock market overreaction. Journal of Banking and Finance, 25, 807-824. 
Nam, K., Washer, K. M., \& Chu, Q. C. (2005). Asymmetric return dynamics and technical trading strategies. Journal of Banking and Finance, 29, 391-418.

Phillips, P. C., \& Perron, P. (1988). Testing for a unit root in time series regression. Biometrika, 75(2), 335-346.

Poterba, J. P., \& Summers, L. H. (1988). Mean reversion in stock prices: Evidence and implications. Journal of Financial Economics, 22, 27-59.

Zhang, B., \& Li. X. (2008). The asymmetric behavior of stock returns and volatilities: Evidence from Chinese Stock Market. Applied Economics Letters, 15, 959-962. 